\title{
The Mask of Sanity Revisited: Psychopathic Traits and Affective Mimicry
}

\author{
Angela Book - Tabitha Methot • Nathalie Gauthier • \\ Ashley Hosker-Field • Adelle Forth • Vernon Quinsey • \\ Danielle Molnar
}

Published online: 14 March 2015

(C) Springer International Publishing 2015

\begin{abstract}
Three studies examined Jones' (Perspectives on Psychological Science, 9, 445-451, 2014) suggestion that psychopathic individuals use mimicry to avoid detection. In study 1 , student, community, and offender participants posed fearful facial expressions while looking at a prototypical fear face. Expressions were coded for facial movements associated with fear and were rated on genuineness by a separate sample of undergraduates. Across samples, psychopathic traits were associated with increased use of typical action units for fearful facial expressions and with genuineness ratings. In study 2 , undergraduates completed the Psychopathic Personality Inventory and told a story about a time when they did something that they should have felt remorseful for but did not. Factor 1 traits were found to positively relate to genuineness scores given by a separate sample of undergraduates. Finally, in study 3 , four videos of false remorse stories told by violent offenders were rated by a sample of undergraduates. The two high factor 1 videos received significantly higher genuineness ratings, supporting the relationship between factor 1 and affective mimicry. Overall, findings suggest that the psychopathic traits (specifically, factor 1) may be associated with the ability to accurately mimic emotional expression (fear and remorse) leading others to perceive emotional genuineness.
\end{abstract}

Keywords Psychopathic traits $\cdot$ Fear $\cdot$ Remorse . Interpersonal deception

\author{
A. Book $(\varangle) \cdot$ T. Methot $\cdot$ N. Gauthier $\cdot$ A. Hosker-Field $\cdot$ \\ D. Molnar \\ Brock University, St. Catharines, ON, USA \\ e-mail: abook@brocku.ca \\ A. Forth \\ Carleton University, Ottawa, ON, USA \\ V. Quinsey \\ Queen's University, Kingston, ON, USA
}

Psychopathy has often been conceptualized as a personality disorder (e.g., Hare 2003) and is comprised of affective (lack of empathy and remorse, shallow emotions), interpersonal (superficial charm, manipulation), and behavioral traits (antisocial behavior, impulsivity, lack of responsibility). Psychopathic traits were originally separated into two factors (Hare 1991): one comprising the interpersonal and affective symptoms and the second consisting of the behavioral items. More recently, a four-factor structure has been suggested, essentially separating the two factors into interpersonal manipulation, callous affect, erratic lifestyle, and antisocial behavior (Hare 2003).

While historically conceptualized as a disorder, numerous researchers have proposed that psychopathy represents an evolutionary adaptation (e.g., Book and Quinsey 2004; Krupp et al. 2013; Mealey 1995). Mealey (1995), for example, suggested that psychopaths evolved to successfully execute deceptions in a social setting, and Hare (2001) referred to psychopaths as "social predators", describing them as parasitic and opportunistic. Previous research suggests that people with psychopathic traits are both exploitive and opportunistic (e.g., Figuerdo et al. 2006; Jonason et al. 2012a, b, c). Jonason et al. found that dark personality traits (including psychopathy) are associated with a fast life history strategy and that psychopathy, specifically, represented an opportunistic and exploitive mating strategy. Further support for the proposal that psychopathic traits may be adaptive comes from research looking at mating strategies, cheating and aggressive behavior, and nepotism in choice of victim, each of which will be reviewed, in turn.

Several researchers have examined the mating strategies of people with psychopathic traits and consistently find that these individuals adopt a short-term mating strategy. Early research by Seto et al. (1997) predicted that psychopaths would use a short, fast mating strategy involving limited investments. They found that psychopathy was positively correlated with 
number of one-night stands and with the use of sexual and nonsexual deception. Further, there was a negative relationship between psychopathy and checking with sexual partners regarding contraception use. They concluded that psychopaths can be considered to be short-term interpersonal strategists.

The findings of Seto et al. have been replicated and extended by Jonason et al. (2009). Because psychopathic traits are associated with impulsivity, manipulation, callous affect, and thrill seeking, Jonason et al. suggested that psychopathic traits would represent an exploitative social style in short-term mating strategies and that people with these traits would not be geared toward long-term meaningful relationships. Findings indicated that psychopathic traits are associated short-term sexual attitudes and behaviors (e.g., regarding casual sex with different partners). Psychopathic traits were significantly positively related to number of sexual partners and with the tendency to follow a short-term mating approach. Similarly, Book et al. (2015) found that the core of the Dark Triad (including psychopathic traits which was almost entirely encompassed in the core) was related to a variety of sexually and socially exploitative behaviors. Presumably, such an exploitive mating strategy would lead to a larger number of offspring with relatively lower parental investment (Glenn et al. 2011). Jonason and Buss (2012) suggest that psychopathy is characterized by a lack of commitment, allowing such individuals to get the benefit, without paying the costs associated with committed relationships. Such a mating strategy is employed by all three personalities in the Dark Triad (narcissism, Machiavellianism, and psychopathy) but is especially true of those with psychopathic traits (Jonason et al. 2012a, b, c). Recent research examining sexual fantasy in relation to the Dark Triad has also supported the link between psychopathy, sexual drive, and impersonal sexual fantasies (e.g., Baughman et al. 2014; Visser et al. 2015). Visser et al. found that psychopathy was associated with wanting novelty and multiple partners in fantasy and in actual behavior.

A successful life history strategy does not only refer to one's own survival and reproduction but also in the survival of others carrying copies of one's genes (e.g., relatives; Krupp et al. 2012). Humans in general are nepotistic, and this appears to be adaptive in nature, as described in kin selection theory (Hamilton 1964a, b). The harming of one's relatives is associated with psychological illness (Daly and Wilson 1988). If psychopathic traits are adaptive, then, nepotism should be apparent in their choice of victims (that is, they should be less likely to victimize individuals who share their genetic material). Krupp et al. (2012) tested this idea and found that psychopathy was associated with an increased risk of harm to nonrelatives and an inhibition toward harming genetic relatives. They also found that psychopaths were less likely than nonpsychopaths to live with relatives, supporting Krupp and colleagues' assertion that they may disperse in order to prevent the injuring of kin.

The adaptive value of psychopathic traits has also been tested in terms of cheating and aggressive behavior. Dawkins (1976) describes the evolutionary benefits of cheating and aggression, and Book and Quinsey (2004) investigated a combination of cheating and aggressive behavior based on two particular strategies described by Dawkins (1976). The strategy of behaving like a co-operator, with bursts of aggression and cheating was labeled the CheaterHawk strategy. In support of the Cheater-Hawk hypothesis, psychopathic traits were associated with the tendency to engage in both cheating and aggression. A second study also found support for the Cheater-Hawk hypothesis (Coyne and Thomas 2008). Primary psychopathy, encompassing traits such as selfishness, callousness, and use of manipulation, was positively related to academic dishonesty, social exclusion, malicious humor, guilt induction, indirect aggression, hostility, physical aggression, verbal aggression, anger, and direct aggression. Secondary psychopathy, including traits such as impulsivity, irresponsibility, and lack of behavioral controls, displayed similar relationships, with the exception of academic dishonesty. However, when primary and secondary psychopathies were included in a single model, it was shown that cheating behavior, indirect aggression, and direct aggression were significant predictors of primary but not secondary psychopathy.

When one is engaging in cheating behaviors, the risk of detection is an important consideration (Dawkins 1976; Frank 1988). Dawkins and Frank describe an evolutionary arms race in which cheaters would evolve to avoid detection, resulting in co-operators evolving to detect cheating, further resulting in cheaters evolving to avoid detection, and so on. Jonason and Webster (2012) describe numerous detection avoidance strategies (e.g., charm, coercion, direct manipulation, and seduction) that would be used by individuals with dark personality traits, including psychopathy, and refer to this collection of tactics as a "veritable toolbox" (p. 524). While psychopathy was correlated with both soft (e.g., charm) and hard (e.g., seduction, direct manipulation) tactics for avoiding detection, the colder tactics were specific to those high on psychopathy (e.g., seduction, coercion, and hardball tactics).

Frank (1988) and Jones (2014) propose another potential strategy that would enable cheaters to avoid detection. Recently, Jones proposed a new theory relating to psychopathy, namely Mimicry-Deception Theory. Of particular relevance to this study is that individuals with psychopathic traits would need to be able to mimic the cooperative behavior of others in order to appear to have legitimacy if they are to take advantage of others, even if the deception is relatively short term. Also related to the idea of cheaters and social predators is the concept of the "successful opportunist" proposed by Frank (1988). It should be noted that Frank's opportunist is 
described as a cheater, so is necessarily exploitive, as well. His theoretical approach begins with a description of how the basic and social emotions evolved as commitment devices (a way to determine how individuals would react in the future). From this, emotions are considered to be a means of communicating and, further, a way to understand whether or not others can be trusted. As people generally avoid interactions with people who seem untrustworthy, part of being a successful opportunist is the appearance of trustworthiness. In this vein, Frank (1988) suggested that successful cheating entails appearing to be honest/trustworthy while availing themselves of opportunities for personal gain at the expense of co-operators. Moreover, he suggested that cheaters are able to appear trustworthy because their cheating and manipulation are masked by feigned emotional displays that act as "commitment devices". Other researchers agree that emotional displays predict future behavior and that these displays are socially motivated (Griffiths 2003; Hinde 1985). Consistent with this view is the fact that emotional expressions are used most often in the company of other people and that they are much more marked in social than in solitary situations (Fridlund 1994). Griffiths (2003) went so far as to say that emotional displays are Machiavellian in that individuals produce displays of emotion when it is advantageous for them to do so. In fact, research does suggest that psychopathic individuals have normal social cognition abilities. For example, they are able to judge complex social emotions based on information from the eye region alone (Richell et al. 2003) and also appear to be able to accurately judge the trustworthiness of an individual using facial cues alone (Richell et al. 2005).

To be successful in an exploitive and opportunistic life history strategy, individuals with psychopathic traits would have to behave in ways that are consistent with other expectations in order to avoid detection. In this regard, it would be important for them to be able to display the full range of basic and social emotions (Frank 1988; Jones 2014). However, it has been suggested that psychopaths may suffer from "emotional poverty" (Cleckley 1941). Cleckley described this attenuated affect as emotional deprivation, emotional isolation, emotional shallowness, and a general lack of emotional response. Importantly, Cleckley also suggested that although psychopaths suffer from pervasive affective deficits, their cognitive understanding of emotion remains intact allowing them to accurately mimic and express what others may perceive as genuine emotion. Seemingly, then, in order to be able to mimic emotions, people with psychopathic traits should show attenuated responses while still being able to identify emotions in others. This has been referred to as "callous empathy" by Book et al. (2007), which implies that those with psychopathic traits may use their understanding of the emotions of others to their own advantage.

Many studies have found attenuated emotional responses in psychopaths (e.g., Patrick et al. 1994) and have concluded that psychopaths suffer from a general poverty of emotion. In one study, psychopaths exhibited significantly less differentiation in heart rate between fearful and neutral sentences than did their nonpsychopathic counterparts (Patrick et al. 1994). From such findings, it has been suggested that psychopaths have a selective deficit in emotional response (Newman et al. 1997). Psychopathic individuals also display an abnormal startle response pattern while viewing affective stimuli (Patrick et al. 1993). More specifically, while they show the same pattern as normal individuals when viewing pleasant and neutral stimuli, they exhibit fewer blinks when presented with unpleasant stimuli. As well, psychopaths appear to be less responsive to distress cues than control subjects (Blair et al. 1997) and exhibit differential brain activation in response to both fear conditioning trials (Birbaumer et al. 2005) and exposure to fearful facial expressions (Deeley et al. 2006). Further, brain imaging studies provide additional support for the notion that psychopathy is associated with specific deficits in the experience of fear (Birbaumer et al. 2005; Veit et al. 2013).

While some researchers ascribe to the notion of general emotional poverty, others have suggested that the deficit is limited to fear (Blair 2005). Plutchik (1995), in a response to Mealey (1995), noted that while psychopaths seem to exhibit attenuated fear responses (Marsh et al. 2011), their other emotions are quite normal. He states that psychopaths experience anger, rage, distrust, and irritability at high intensities according to physiological, behavioral, and self-report measures. Further, psychopaths do not seem to have deficits in terms of positive emotions. Research on response perseveration has shown that psychopaths are reward-oriented (Newman et al. 1987), making it unlikely that psychopaths would have attenuated positive emotions, such as pleasure and happiness. Psychopathic individuals also tend to be sensation seekers and risk takers, both of which are associated with reward centers in the brain (Levenson 1990). Further, research has shown that psychopaths do not exhibit impaired positive emotional reactivity (Patrick et al. 1993). In fact, they show a normal attenuation of the startle reflex during the viewing of pleasant stimuli, a finding replicated by Levenston et al. (2000). The most consistent finding in the above studies is an attenuation of fear. This has clear implications for being able to take risks and exploit others, in that fear has been suggested as a mechanism for controlling such behaviors (e.g., Blair 2005).

Given that psychopaths experience attenuated fear, how do they manage to avoid detection (i.e., appear normal) in interpersonal interactions, especially in fear-inducing situations? Frank (1988) stated that in order for such emotional displays to act as commitment devices, they must be relatively honest representations, and the honesty of facial expressions of emotion is supported by cross-cultural data showing universality (Ekman 1970). Also, it has been found that some emotional expressions are very difficult to emulate (Ekman 1992). 
However, Ekman $(1992,1993)$ did find that some individuals are able to fabricate these expressions in the absence of emotion. In other words, it is possible to learn to produce these facial expressions, as well as the appropriate situations in which to display them. Thus, even though psychopaths may experience attenuated fear, it would be possible for psychopaths to learn to mimic fear displays. Obviously, for such learning to occur, psychopathic individuals would have to be able to recognize fear in other people. The research examining affect recognition in this population has been mixed. For example, Blair et al. (2004) found deficits in fear recognition, Woodworth and Waschbusch (2008) found that people with psychopathic traits were better at recognizing fear, and Glass and Newman (2006) found no evidence for a deficit or an advantage. A meta-analysis of the small number of studies available shows extremely small deficits in recognition of all emotions $(r<.10)$, indicating that any existing deficit is unremarkable (Wilson et al. 2011).

A second emotion that is thought to be lacking in individuals with psychopathic traits is remorse; in fact, this is one of the cornerstones of the construct (Cleckley 1941). Similar to the argument for learning to mimic fear, a successful manipulator would need to be able to feign remorse in certain contexts in order to appear trustworthy and to gain the cooperation of those around them. Certain emotions, such as remorse and shame, prompt individuals to behave in a moral or honest fashion (Frank 1988). For most people, the experience of these so-called moral emotions as a result of committing a dishonest behavior is sufficiently unpleasant that it prompts them to avoid committing dishonest actions in the future (Baumeister and Lobbestael 2011; Frank 1988). Thus, most people who can experience remorse or shame prefer to behave honestly so as to avoid the unpleasantness of these emotions. Again, Frank describes emotions such as remorse as "commitments, " in that they "commit" us to behave in ways that are more honest than we might otherwise be inclined to behave.

Most individuals are capable of feeling social emotions and therefore generally tend to behave honestly, but this is not the case for all individuals (e.g., Frank 1988). Individuals who do not experience these emotions lack both the commitment to behave honestly and also the resulting signal to others of the propensity to behave honestly. Thus, these individuals may appear untrustworthy and could lose out on the potential benefits of interacting with others who do behave honestly. Opportunists/cheaters (who lack these emotions) may therefore need to feign moral emotions in order to appear trustworthy and encourage others to cooperate with them. The ability to successfully fake remorse would, therefore, confer an adaptive benefit on those who wish to exploit and manipulate others.

By feigning remorse, individuals who lack these emotions may profit from appearing to be trustworthy while retaining the ability to pursue their own interests (without being hampered by any real emotions or concerns; Frank 1988). A further benefit may be that an individual who wants to deceive others will be more likely to get away with the deception if he appears to be trustworthy. In fact, individuals who are particularly predisposed to behave dishonestly might have developed the ability to successfully feign emotions such as remorse (Trivers 1971).

We conducted three studies to examine whether individuals scoring higher on psychopathy were (a) able to produce facial displays of fear (study 1) and (b) to appear genuine while feigning remorse (studies 2 and 3). In general, we expected that factor 1 , as it encompasses the interpersonal and affective psychopathic traits (e.g., shallow affect, lack of empathy, lack of remorse, and manipulativeness), would be positively related to the ability to feign/mimic emotions. We did not have any specific predictions for factor 2 , which is comprised of such traits as impulsivity and poor behavioral controls. More specifically, if emotional displays are central to avoiding detection as an opportunist (Frank 1988), individuals with psychopathic traits, who would have the unique experience of having to learn to mimic fear, should presumably be better at posing fearful facial expressions than other individuals. In studies 2 and 3, we similarly predicted that people higher on psychopathic traits would be perceived as more genuine when feigning remorse. Study 2 examined this issue in a sample of undergraduates, and study 3 employed video stimuli from a sample of violent offenders scoring (a) high on factor 1 and factor 2, /9b) high on factor 1 and low on factor 2, (c) low on factor 1 and high on factor 2, and (d) low on both factors, comparing the genuineness scores given by a sample of undergraduates for the four videos.

\section{Study 1}

Methods

\section{Phase 1: Objective Accuracy and Stimuli Collection}

Participants Inmates. A larger study recruited 59 male inmates from a federal correctional facility in Ontario. Of those, 31 agreed to participate in the present study (53\%). Participants in this sample ranged from 19 to 58 years of age $(M=31.55, S D=10.57)$.

Community Participants. Fifty males from the community were recruited through a newspaper advertisement. The advertisement asked for adult males to participate in a research project examining recognition and expression of emotions. Interested individuals were told that they would be paid $\$ 20$ for participation. The age of community participants ranged from 19 to $63(M=32.28, S D=13.23)$. Participants were recruited in Kingston, Ontario. Within and around this community, there are several federal penitentiaries and a substantial 
number of parolees remain in the area. As mentioned, participants were also offered compensation for their time, and sessions were booked on weekdays, increasing the likelihood that participants were unemployed. The combination of these factors leads to a sample of "community" individuals that would likely score higher on measures of psychopathy than one would find in other communities. In fact, previous research has found that community members in Kingston score higher on measures of antisociality than is seen in samples of undergraduates (Book and Quinsey 2004).

Student Sample. Because of the possible unusual nature of the community sample, an undergraduate student sample was also recruited. Forty undergraduates (all male) were recruited to participate in the present study ranging in age from 18 to 31 $(M=20.47, S D=3.70)$.

Given the possibility that race would affect the accuracy of emotion categorization (Matsumoto and Ekman 1988), across each sample, all participants recruited were Caucasian.

Materials Measures of Psychopathy. Psychopathy ChecklistRevised scores (PCL-R; Hare 1991, 2003) were scored by the first author based on an interview with the inmate, as well as from institutional files. The PCL-R consists of two factors: Factor 1 mainly assesses emotional and interpersonal symptoms, and factor 2 measures social deviance. Where file information included a previous PCL-R assessment $(N=17)$, the previous score was compared to the ratings from the present study for the purposes of reliability analysis. Interrater reliability for total, factor 1 , and factor 2 scores were very good (intraclass correlations $(I C C s)=.95, .94, .97$, respectively). Total PCL-R scores ranged from 3 to 36 out of a possible 40 , with a mean of $17.30(S D=7.61)$.

Levenson's Self Report Psychopathy Scale (LSRP; Levenson et al. 1995) was used to measure psychopathic traits in all three samples. Scores on each item range from 1 (strongly disagree) to 4 (strongly agree). Higher scores represent increasing psychopathy. There are two domains: primary psychopathy and secondary psychopathy. The first purports to measure a selfish, callous, uncaring, and manipulative orientation toward others ("Success is based on survival of the fittest; I am not concerned with the losers"), while the second measures impulsivity and poor behavioral controls ("I find myself in the same kinds of trouble, time after time").

Intelligence Measure. The vocabulary subscale of the Kaufman Brief Intelligence Test (K-BIT; Kaufman and Kaufman 1990) was used to as an index of general intelligence. This subscale has been found to be both reliable and valid; for example, scores correlate .83 with the WAIS verbal subscale (Naugle et al. 1993). Scores on the K-BIT vocabulary subscale were obtained to ensure that intelligence differences did not account for relationships between study variables. The K-BIT was not administered in the student sample, as K-BIT scores did not predict the ability to feign facial expressions in the other two samples.

Prototypical Fearful Facial Expression. The Japanese and Caucasian Facial Expressions of Emotion and Neutral Faces (Matsumoto and Ekman 1988) is a compilation of 56 Japanese and Caucasian facial expressions and 56 neutral expressions. These color photographs of affect have been shown to be reliable and valid when individuals are asked to categorize them (Matsumoto and Ekman 1988). A prototype of a fearful face from the male Caucasian set was used for the present study. A video camera (Sony Digital-8, model \# DCR-TRV 320) was used to take photographs of participants posing a fearful facial expression and a neutral expression. As per methods described by Kolb and Taylor (2000), participants were shown the prototypical fear face (Matsumoto and Ekman 1988) and were asked to reproduce it while the video camera recorded the entire procedure. The video camera was placed so that photographs would be frontal. The prototypical photographs were in view for the entire procedure. Participants were instructed to raise their hand to signal that they had mimicked the prototype to the best of their ability, and they were not given any feedback on their efforts. Still, photographs were then captured from the video footage. Photographs were captured at the point right before the participant raised their hand.

Facial Affect Coding System. According to Ekman and Friesen (1978), facial expressions of emotion typically contain several key features. For example, fearful faces should include a variety of characteristics, including wide eyes, raised eyebrows, and an open mouth. Each possible feature for each emotion was coded as a 0 (not present), 1 (slightly present), or a 2 (definitely present). A composite score was created for each posed photograph, by adding up the scores for each action unit. This coding was intended to be an objective measure of posing accuracy. Interrater reliability for this use of the Facial Action Coding system (FACS) was found to be very $\operatorname{good}(I C C=.89$ to .93 across samples). Hereafter, the composite score is referred to as the FACS score.

\section{Phase 2: Genuineness Ratings}

Participants Forty-four undergraduate students rated the facial expressions elicited from the inmate and community samples, and a separate sample of forty undergraduate students rated the facial expressions from the student sample.

Procedure Participants were told that the facial expression was meant to represent "fear". They were asked to rate each face on how genuine the emotion appeared to be, on a scale from 1 to 10 , with 10 indicating that the emotion appeared to be quite genuine. Alpha coefficients were calculated to see whether ratings given to each photograph by the undergraduates were correlated with one another. In this analysis, raters 
were the participants, and each photograph was considered to be an "item". Coefficient alphas ranged from .90 to .95 , indicating that participants made similar judgments about individual photographs. Because individuals gave similar ratings to each face, average "genuineness" scores were calculated. Ratings were averaged over the undergraduate participants to produce genuineness scores for each individual photograph. Correlations were calculated between the averages of these ratings and the psychopathy scores (PCL-R and LSRP) for the individual in the photograph.

Results

\section{Group Differences}

Means and standard deviations for the variables discussed in this section are listed in Table 1. Interestingly, while inmates did score higher than community participants on psychopathy (as measured by the LSRP), the differences were not significant $(t(79)=1.10, p=.27 ; t(79)=1.14, p=.26$ and $t(79)=1.30$, $p=.20$, for primary, secondary, and total psychopathy, respectively). Because there were no significant differences in LSRP scores, analyses for the LSRP used the community and inmate samples combined. However, the student sample was analyzed separately, as the undergraduate sample differed significantly from the other samples on subscale and total psychopathy scores $(t(119)=6.45, p<.001, t(119)=10.68, p<.001$ and $t(119)=7.20, p<.001$ for primary, secondary, and total psychopathy scores, respectively).

Table 1 Descriptive statistics for measures of psychopathy used in study 1

\begin{tabular}{lllll}
\hline Measure & Group & N & Mean & SD \\
\hline PCL-R & & & & \\
$\quad$ Total score & Institutional & 31 & 17.30 & 7.61 \\
Factor 1 & Institutional & 31 & 4.93 & 4.01 \\
Factor 2 & Institutional & 31 & 9.50 & 4.34 \\
Levenson's SRP & & & & \\
$\quad$ Total score & Student & 40 & 42.25 & 9.87 \\
Primary psychopathy & Student & 40 & 25.61 & 4.86 \\
Secondary psychopathy & Student & 40 & 16.55 & 3.21 \\
Levenson's SRP & & & & \\
$\quad$ Total score & Community & 50 & 54.15 & 9.40 \\
Primary psychopathy & Community & 50 & 32.30 & 6.50 \\
$\quad$ Secondary psychopathy & Community & 50 & 21.72 & 4.96 \\
Levenson's SRP & & & & \\
$\quad$ Total score & Institutional & 31 & 57.05 & 10.05 \\
Primary psychopathy & Institutional & 31 & 34.18 & 7.32 \\
Secondary psychopathy & Institutional & 31 & 22.86 & 4.77 \\
\hline
\end{tabular}

$P C L-R$ Psychopathy Checklist-Revised (Hare 2003)

\section{Psychopathy and Accuracy}

Table 2 contains the correlations between measures of psychopathy and both objective (FACS coding) and subjective (genuineness) measures of accuracy of facial expressions. Partial correlations were used for examining psychopathy factors, given the inherent overlap between them (Hare 2003). Because primary psychopathic traits were predicted to be positively related to accuracy of posed fearful facial expressions, tests of this relationship were directional (one-tailed). Other tests are two-tailed. As expected, psychopathy among the offenders (as measured by the PCL-R) was positively correlated with accuracy of posing fearful faces (based on the composite score derived from the FACS coding system; Ekman and Friesen 1978) $(r(28)=.31, p=.05)$. Further, factors 1 and 2 of the PCL-R had similarly medium effect sizes but were nonsignificant $(r(28)=.27, p=.07 ; r(28)=.23, p=.11$, respectively). Finally, the correlation between factor 1 and ratings of genuineness was of a similar size and nonsignificant $(r(28)=.23, p=.11)$.

In the combined inmate/community sample, objective accuracy scores and ratings of genuineness were positively correlated with primary psychopathy, in line with expectations $(r(75)=.31, p=.003 ; r(75)=.32, p=.002$, for objective scoring

Table 2 Correlations between measures of psychopathy and accuracy of posed facial expressions (study 1)

\begin{tabular}{|c|c|c|}
\hline & Objective scoring & Subjective ratings \\
\hline \multicolumn{3}{|l|}{ Inmate sample } \\
\hline \multicolumn{3}{|l|}{ PCL-R } \\
\hline Total & $.31 *$ & .02 \\
\hline Factor 1 & .27 & .22 \\
\hline Factor 2 & .23 & -.16 \\
\hline \multicolumn{3}{|c|}{ Community/inmate samples } \\
\hline \multicolumn{3}{|l|}{ LSRP } \\
\hline Total & .07 & .09 \\
\hline Primary & $.31 * *$ & $.32 * *$ \\
\hline Secondary &.$-.25 *$ & .005 \\
\hline \multicolumn{3}{|l|}{ Student sample } \\
\hline \multicolumn{3}{|l|}{ LSRP } \\
\hline Total & $.38 * *$ & $.34 *$ \\
\hline Primary & $.38 * *$ & $.35 *$ \\
\hline Secondary & .20 & .17 \\
\hline
\end{tabular}

Correlations discussed in the results are bolded, and italicized correlations have $p$-values between .06 and .11. Objective scoring is based on FACS coding of posed facial expression. Subjective scores are ratings of genuineness given by separate sample of undergraduate students. Sample sizes for inmates $(N=31)$, community/inmate samples $(N=77)$, and student sample $(N=40)$

$P C L-R$ Psychopathy Checklist-Revised (Hare 2003), LSRP Levenson Self-Report Scale (Levenson et al. 1995).

${ }^{*} p<.05, * * p<.01$, one-tailed 
and genuineness, respectively). Secondary psychopathy, on the other hand, was negatively correlated with objective accuracy $(r(75)=-.25, p=.03)$ and not significantly related to ratings of genuineness $(r(75)=.01, p=.96)$. As could be expected from this pattern, the relationship between LSRP total and both measures of accuracy was near zero and nonsignificant. In the student sample, objective accuracy was significantly correlated with both total LSRP and primary psychopathy $(r(38)=.38, p=.01 ; r(38)=.37, p=.01)$. Similarly, subjective ratings of how genuine the expressed emotion were positively correlated with total LSRP and primary psychopathy $(r(38)=.34, p=.02 ; r(38)=.35, p=.01)$.

\section{Discussion for Study 1}

As predicted, psychopathy, as measured by the PCL-R total, was significantly and positively correlated with objective (FACS score) ratings of the accuracy of posed fearful facial expressions. Similarly "medium" effect sizes were observed for subjective ratings and factor 1 psychopathic traits, but this relationship did not reach the threshold for significance, likely due to the small sample size. The same pattern of findings was observed for the student sample, where objective and subjective accuracies were significantly positively correlated with total and primary psychopathy. For the combined community/inmate sample, primary psychopathy was related to increased accuracy (objective and subjective).

The results of this study provide some support for the idea that psychopathic traits (especially traits encompassed in factor 1 or primary psychopathy) may be positively related to the ability to feign fearful facial expressions. While the findings support Frank's (1988) assertion that successful opportunists should be able to mimic emotions, it is essential to examine emotions that directly relate to the evolution of cooperation, such as remorse. As such, we designed studies 2 and 3 to examine psychopathic traits in relation to mimicry of remorse.

\section{Study 2}

Method

\section{Participants}

Participants were 72 students ( $57 \%$ female; mean age $=22.45$; $S D=1.25$ ) from a Canadian university, who participated in return for partial course credit.

\section{Materials}

Videos Forty-five short video clips of individuals telling true stories while feigning remorse. Forty-five male students from a Canadian university, participated in a study in which they agreed to be videotaped while telling false remorse stories. That is, the students told stories that were true in terms of content, but they feigned remorse regarding these stories. In order to encourage students to fake remorse as well as they were able, students were told that they would receive lottery tickets in return for successfully faking remorse. The students in the video clips ranged from 17 to 23 years of age $(M=21.32 ; S D=1.14)$.

Psychopathic Personality Inventory-Short Form (PPI$S F)$ Students who provided the false remorse videos also completed the Psychopathic Personality Inventory-Short Form (PPI-SF; Lilienfeld and Hess 2001). The PPI-SF is a 56-item self-report measure of psychopathy that is appropriate for use in noncriminal samples. Items are rated on a 4-point Likert scale $(1=$ false, $2=$ mostly false, $3=$ mostly true, $4=$ true $)$, with higher scores reflecting higher levels of psychopathic traits. According to a factor analysis conducted by Benning et al. (2003), the PPI can be divided into two factors mirroring factors 1 and 2 of the psychopathy checklist. One factor includes the stress immunity, social potency, and fearlessness subscales, while the other is comprised of impulsive nonconformity, blame externalization, Machiavellian egocentricity, and carefree nonplanfulness. For ease of interpretation, we are referring to these two factors as factor 1 and factor 2, respectively, within this paper.

Genuineness Ratings Participants rated the genuineness of the remorse displayed in the videos on a 10-point Likert scale, ranging from 1 (not at all genuine) to 10 (completely genuine).

\section{Procedure}

Participants were provided with a verbal definition of remorse at the start of the study. Each participant rated a random selection of 15 of the videos. Following each video, participants were asked to rate the degree of genuineness of the remorse expressed by the individual in the video. Each video was rated by 24 participants. Participants were not informed that the targets in the videos were lying. Average genuineness ratings exceeded the midpoint of the scale $(M=5.14, S D=1.64)$.

Results

For each video, a mean rating of genuineness was computed. Correlational analyses were conducted between the mean ratings of genuineness of remorse and the PPI-SF scores of the individuals in the videos. The correlation between psychopathy (PPI-SF total scores) and rated genuineness of remorse was not significant $(r(44)=-.01, p=.95)$. Bivariate correlations indicated that factor 1 was uncorrelated with genuineness ratings $(r(44)=.14, p=.36)$, while factor 2 was negatively and marginally related to genuineness $(r(44)=-.24, p=.10)$. 
Because this pattern is suggestive of suppression (e.g., the correlations were in the opposite directions), we decided to examine partial correlations and found that factor 1 was positively correlated with genuineness, $r(43)=.42, p=.004$ (controlling for factor 2), while factor 2 scores were negatively correlated with genuineness, $r(43)=-.32, p=.03$ (controlling for factor 1).

\section{Discussion for Study 2}

The results of study 2 provided some support for the prediction that interpersonal and affective traits would positively correlate with ratings of genuineness. However, this was only true when controlling for sactor 2 . Combined with the nearzero correlation between total LSRP and perceived genuineness and the negative relationship between factor 2 and genuineness, it would seem that factor 2 suppresses the relationship between factor 1 and perceived genuineness. In contrast, people scoring high on factor 2 were perceived as less genuine when faking remorse. In order to determine whether the results of study 2 can be replicated and generalized across samples, we undertook a further study of feigned remorse. In study 3 , we sought to determine whether a sample of raters would show the same tendency when viewing videos of inmates attempting to mimic remorse.

\section{Study 3}

Methods

\section{Participants}

Participants were 70 students $(86 \%$ female, mean age $=$ 21.14 years, $S D=4.63$ ) from a Canadian university, who participated in exchange for partial course credit.

\section{Materials}

Hare Psychopathy Checklist-Revised The PCL-R is a 20-item rating scale that assesses the interpersonal, affective, and behavioral features of psychopathy. Trained raters rate the presence of each item based on a semi-structured interview and file review. Each item is scored on a 3-point scale, with final scores ranging from 0 to 40 . A score of 25 to 30 is accepted as indicative of psychopathy (Hare 2003). Scores on the PCL-R have demonstrated levels of internal consistency and high interrater reliability (Hare 2003). This measure is divided into two main factors. Factor 1 (F1) is composed of two subscales: callous affect and interpersonal manipulation. Factor 2 (F2) is also composed of two subscales: antisocial behavior and erratic lifestyle (Hare and Neumann 2008). The PCL-R scores were on file at the institution where data was collected.
Videos Materials for this study included four short video clips of feigned remorse stories (approximately $2 \mathrm{~min}$ each in length). These videos were chosen in order to have one video to represent each of four different combinations of psychopathy factors: (a) high F1/high F2, (b) high F1/low F2, (c) low F1/high F2, and (d) low F1/low F2. All of the inmates were violent offenders (i.e., at least one violent offense) in a maximum security institution. Inmates were instructed to tell a story of a true event, in which they had done something which would warrant remorse but in which they had not actually felt remorseful. They were instructed instead to feign the emotion of remorse in relation to the event.

T-scores (as given in the PCL-R second edition manual; Hare 2003) at or below 44.5 were considered to be "low" (corresponding to the 30th percentile), and T-scores at or above 55 were considered to be "high" (corresponding to the 70th percentile).

Genuineness Ratings Participants rated the genuineness of the remorse expressed in each video on a Likert scale ranging from 1 ("not at all genuine") to 7 ("very genuine"). Mean genuineness ratings for the targets exceeded the midpoint of the scale $(M=3.75, S D=1.44)$, similar to what was found in study 2.

\section{Procedure}

Participants were provided with a verbal definition of remorse at the start of the session. Following each video, participants rated the degree of genuineness of the remorse expressed in the video. Participants were not informed that the inmates in the videos were faking remorse.

\section{Results}

A repeated measures analysis of variance (ANOVA) was employed to investigate whether respondent's ratings of genuineness varied as a function of the stimuli's factor 1 and factor 2 scores. Results from the multivariate analysis were statistically significant Wilk's $\lambda=.221, p<.001$. Results examining the main effect demonstrated that scores of genuineness did vary as a function of psychopathy level $(F(3,207)=88.34$, $p<.001, \eta p^{2}=.56$ ). Specifically, participants rated individuals who were high in factor 1 (video 2 and video 4) as more genuine than those rated low in factor 1 (video 1 and video 3; see Fig. 1). Pairwise comparisons employing a Bonferroni correction for family wise error rate were carried out to determine the source of the differences. As seen in Table 3, all pairwise comparisons were significant, with high F1/high F2 being rated as most genuine, followed by high F1/low F2, low F1/low F2, and low F1/high F2. 
Fig. 1 Genuineness ratings for targets at varying levels of psychopathic traits in study 3

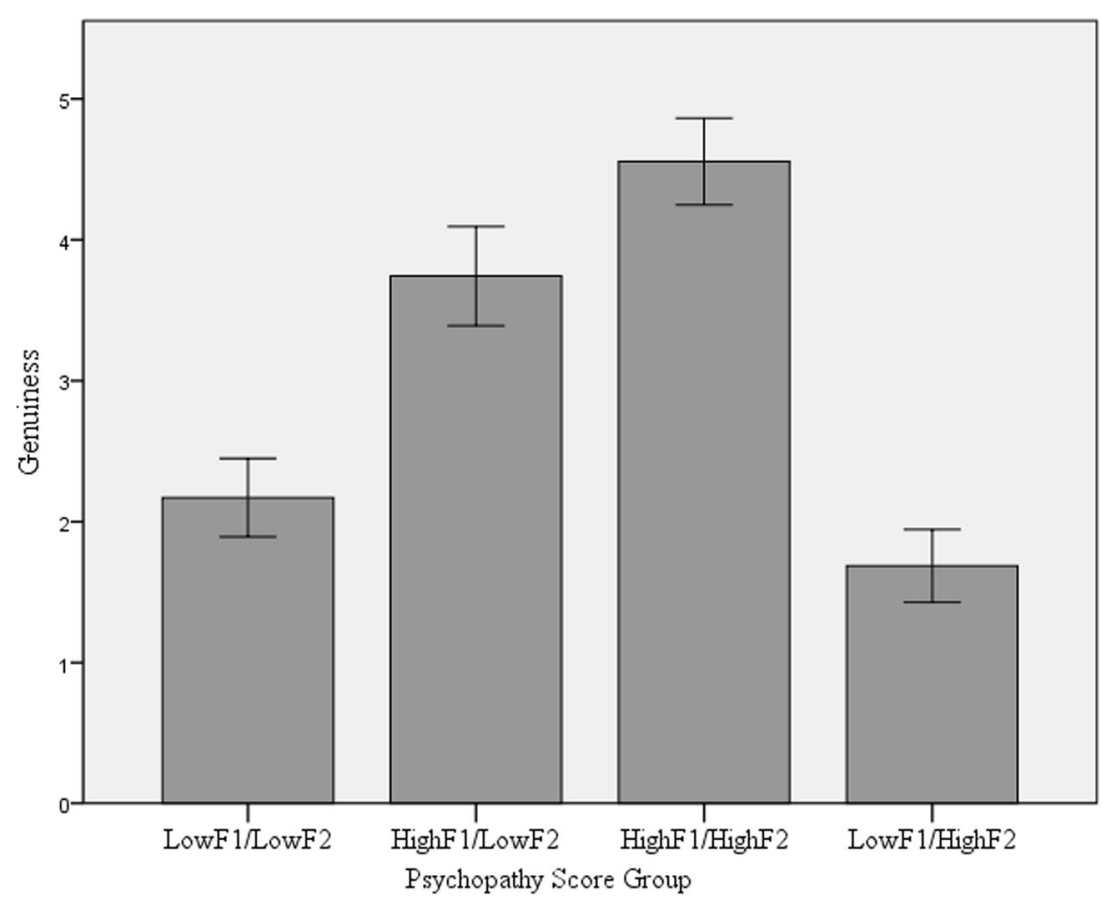

\section{Discussion}

The results of the three studies conducted provided some support for Frank's (1988) assertion that successful opportunists should be adept at affective mimicry in the absence of that emotional experienceand for Jones' Mimicry-Deception Theory (2014). The findings of the first study suggest that people high on the interpersonal/affective traits of psychopathy may be better able to feign fearful facial expressions, and studies 2 and 3 suggest that the same is true of a more social emotion, namely remorse.

The results, then, also offer some support for the notion of psychopaths as social predators, which has been suggested by numerous researchers (e.g., Book and Quinsey 2004; Book et al. 2007; Hare 2001; Mealey 1995). Factor 1 scores, specifically, seem to be associated with an increased ability to feign both fear and remorse. This is in line with the idea that successful opportunists/cheaters should be able to appear trustworthy by mimicking the social emotions genuinely experience by others (Frank 1988; Jones 2014). Certain elements of psychopathy, in particular, those related to factor 1 including deceptiveness, manipulativeness, and callousness, may play a role in facilitating affective mimicry. Successful affective mimicry (drawing from Frank 1988 and Jones 2014) would allow these individuals to appear more trustworthy than they would appear otherwise, which may help them to manipulate and deceive others for their own benefit. Of course, affective mimicry is only one of many possible strategies for avoiding detection (Jonason and Webster 2012), and future research should investigate whether factor 1 traits are also associated with Jonason and Webster's veritable toolbox (p. 524) of strategies, including seduction, coercion, hardball tactics, and charm. Psychopaths may also use other tactics such as assertiveness, direct manipulation, and ingratiation (Jonason et al. 2012a, b, c).

The fact that psychopaths are able to appear normal in terms of displaying emotions that they may not be experiencing gives credence to Cleckley (1941), where he suggested
Table 3 Pairwise comparisons between videos with Bonferroni correction for family-wise error rate (study 3)

\begin{tabular}{lllllll}
\hline Video 1 & Video 2 & $M_{\text {diff }}$ & Se $_{\text {diff }}$ & $p$ value & $\mathrm{CI}_{\text {upper }}$ & $\mathrm{CI}_{\text {lower }}$ \\
\hline LowF1LowF2 & LowF1HighF2 & -0.486 & 0.169 & 0.032 & -0.027 & -0.944 \\
& HighF1LowF2 & -1.571 & 0.201 & $<.001$ & -2.12 & -1.03 \\
& HighF1HighF2 & -2.386 & 0.19 & $<.001$ & -2.91 & -1.87 \\
LowF1HighF2 & HighF1LowF2 & -2.06 & 0.22 & $<.001$ & -2.65 & -1.47 \\
& HighF1HighF2 & -2.87 & 0.21 & $<.001$ & -3.43 & -2.31 \\
HighF1LowF2 & HighF1HighF2 & -0.81 & 0.22 & 0.03 & -1.41 & -0.022 \\
\hline
\end{tabular}


that psychopaths are capable of understanding and mimicking the full range of emotions. Further, he felt that their inability to experience emotion as fully as other individuals did not preclude a cognitive understanding of emotions in other people, which may help explain the psychopath's proclivity toward exploiting others. Other researchers have suggested that individuals with psychopathic traits are able to perceive emotional states in others but do not have the normal affective reaction to the emotions of others. Book et al. (2007) refer to this as "callous empathy" and suggest that this enables psychopaths to use affective information to their own ends. Lorenz and Newman (2002) also commented on this contradiction, labeling it the "emotion paradox". They felt that this combination may make psychopathic individuals ideally suited to manipulate and deceive others to their own ends. Such a statement is in agreement with theorists, such as Mealey (1995) who suggested that psychopaths are interpersonal cheaters. Not only are psychopaths manipulative and deceptive (Hare 1993), they are able to appear normal in their displays of emotion, making them less detectable as opportunists (Frank 1988).

The findings from the present studies also have implications in the conceptualization of emotional expression. It would seem that the expression of emotion is not necessarily dependent upon affect and has a social presentation and communicative component that is separate from the emotion itself, as suggested by others (e.g., Fridlund 1994; Griffiths 2003; Hinde 1985). This claim is further supported by a study by Patrick et al. (1993) who found that psychopathic individuals were impaired in affective reactivity (e.g., physiological arousal) but did not differ from controls in facial reactivity (i.e., corrugator EMG) to unpleasant pictures.

Given the evidence that psychopaths experience attenuated fear (Patrick et al. 1994) and remorse (Hare 2003), it is likely that their ability to emulate these emotions would be a learned skill. To be able to learn to mimic fearful facial expressions, psychopaths would have to be able to recognize emotions in other individuals. In other words, their theory of mind (ToM; Premack and Woodruff 1978) would necessarily be intact. In fact, psychopaths do not show any deficits in ToM (Richell et al. 2003). Further support for an intact ToM comes from research showing that psychopathy is positively associated with the ability to judge affect from facial expressions and to make attributions of vulnerability and assertiveness after observing an interpersonal interaction (Book et al. 2007). As well, in a study conducted by Copestake et al. (2013) that examined psychopathic traits in relation to emotional intelligence, psychopathic traits were found to correlate with an inability to experience some emotions, but all other emotional intelligence components were intact (including the ability to identify emotions in others).

\section{Limitations and Future Directions}

Because we had relatively small samples in study 1 (e.g., only 31 inmates agreed to be videotaped), the finding that people with psychopathic traits may be better at mimicking fearful facial expressions needs to be replicated in a larger sample. Even with a consistent medium effect size, some of the correlations were nonsignificant.

Another limitation concerns realism and generalizability of the stimuli that were used in study 1 . Posed facial expressions are typically easier to recognize than genuine expressions (Allen and Atkinson 1981). Further, they do not share all of the facial action units associated with genuine emotional expression (Hager and Ekman 1985). Finally, Ekmanet al. (1981) found that genuine facial expressions were more symmetrical and less lateralized than posed expressions of emotion. Because of the differences between genuine and posed facial expressions of affect, it will be important to replicate these findings employing more naturalistic facial expressions as prototypes. Collecting these data would be inherently more difficult, but the results would be more generalizable.

Also relevant to the issue of generalizability, facial expressions do not operate in an interpersonal vacuum. Other cues to emotion, motivation, and intention always exist in an interpersonal situation. It is important, then, to look at other nonverbal and verbal behaviors that might be associated with fear. To accomplish this, one could have participants tell a made-up story about a time when they were afraid (while being videotaped). The individuals in the videos could then be rated on believability and emotional intensity. This would determine whether the findings study 1 generalize to more complex stimuli. As we did find similar results for remorse using just this type of design, it is likely that the results would generalize.

One important issue in the study of psychopathic traits is the overlap between these and other dark personality traits. Numerous researchers have found that there is significant overlap between the three members of the Dark Triad, which is made up of narcissism, Machiavellianism, and psychopathy (e.g., Paulhus and Williams 2002), and have attempted to explain the "core" of the Dark Triad because of this overlap (for a review of the various explanations of the core, see Book et al. 2015). Book et al. labeled the core as "evil", and found that scores on the core were correlated with social and sexual exploitation of others. Further, when the various explanations of the core were tested against one another, the best fitting model was the HEXACO model of personality (Book et al 2015), with Honesty Humility accounting for most of the variability. Thus, future research should also examine whether Honesty Humility is related to affective mimicry.

To summarize, the present studies found support for Frank's (1988) assertion that successful opportunists use insincere emotional displays to appear trustworthy and Jones' (2014) suggestion that people with psychopathic traits make 
use of affective mimicry in order to avoid detection. More specifically, individuals with psychopathic traits may be able to express fraudulent emotions that appear genuine to the people around them. Cleckley's (1941) use of the title "The Mask of Sanity" may be more appropriate than even he knew.

\section{References}

Allen, V. L., \& Atkinson, M. L. (1981). Identification of spontaneous and deliberate behavior. Journal of Nonverbal Behavior, 5, 224-237.

Baughman, H., Jonason, P., Veselka, L., \& Vernon, P. (2014). Four shades of sexual fantasies linked to the Dark Triad. Personality and Individual Differences, 67, 47-51. doi:10.1016/j.paid.2014.01.034.

Baumeister, R. F., \& Lobbestael, J. (2011). Emotions and antisocial behavior. Journal of Forensic Psychiatry \& Psychology, 22, 635-649. doi:10.1080/14789949.2011.617535.

Benning, S., Patrick, C., Hicks, B., Blonigen, D., \& Krueger, R. (2003). Factor structure of the Psychopathic Personality Inventory: validity and implications for clinical assessment. Psychological Assessment, 15, 340-350. doi:10.1037/1040-3590.15.3.340.

Birbaumer, N., Veit, R., Lotze, M., Erb, M., Hermann, C., Grodd, W., \& Flor, H. (2005). Deficient fear conditioning in psychopathy: a functional magnetic resonance imaging study. Archives of General Psychiatry, 62, 799-805. doi:10.1001/archpsyc.62.7.799.

Blair, R. J. R. (2005). Applying a cognitive neuroscience perspective to the disorder of psychopathy. Development and Psychopathology, 17, 865-891. doi:10.1017/S0954579405050418.

Blair, R., Jones, L., Clark, F., \& Smith, M. (1997). The psychopathic individual: a lack of responsiveness to distress cues? Psychophysiology, 34, 192-198.

Blair, R., Mitchell, D., Peschardt, K., Colledge, E., Leonard, R., Shine, J., et al. (2004). Reduced sensitivity to others' fearful expressions in psychopathic individuals. Personality and Individual Differences, 37, 1111-1122. doi:10.1016/j.paid.2003.10.008.

Book, A. S., \& Quinsey, V. L. (2004). Psychopaths: cheaters or warrior-hawks? Personality and Individual Differences, 36, 33-45. doi:10.1016/S0191-8869(03)00049-7.

Book, A. S., Quinsey, V. L., \& Langford, D. (2007). Psychopathy and perception of affect and vulnerability. Criminal Justice and Behavior, 34, 531-544.

Book, A. S., Visser, B., \& Volk, A. (2015). Unpacking evil: claiming the core of the Dark Triad. Personality and Individual Differences, 73, 29-38. doi:10.1016/j.paid.2014.09.016.

Cleckley, H. (1941). The mask of sanity: an attempt to clarify some issues about the so called psychopathic personality. St. Louis: Mosby.

Copestake, S., Gray, N., \& Snowden, R. (2013). Emotional intelligence and psychopathy: a comparison of trait and ability measures. Emotion, 13, 691-702. doi:10.1037/a0031746.

Coyne, S. M., \& Thomas, T. J. (2008). Psychopathy, aggression, and cheating behavior: a test of the Cheater-Hawk hypothesis. Personality and Individual Differences, 44, 1105-1115. doi:10.1016/j.paid.2007.11.002.

Daly, M., \& Wilson, M. (1988). Evolutionary social psychology and family homicide. Science, 242, 519-524.

Dawkins, R. (1976). Theselfish gene. New York City: Oxford University Press.

Deeley, Q., Daly, E., Surguladze, S., Tunstall, N., Mezey, G., Beer, D., Ambikapathy, A., Robertson, D., \& Murphy, D. G. (2006). Facial emotion processing in criminal psychopathy. Preliminary functional magnetic resonance imaging study. British Journal of Psychiatry, $189,533-539$.
Ekman, P. (1970). Universal facial expressions of emotion. California Mental Health Research Digest, 8, 151-158.

Ekman, P. (1992). Telling lies: clues to deceit in the marketplace, marriage, and politics (2nd ed.). New York: W.W. Norton.

Ekman, P. (1993). Facial expression and emotion. American Psychologist, 48, 384-392.

Ekman, P., \& Friesen, W. V. (1978). Facial action coding system: a technique for the measurement of facial movement. Palo Alto: Consulting Psychologists Press.

Ekman, P., Hager, J. C., \& Friesen, W. V. (1981). The symmetry of emotional and deliberate facial actions. Psychophysiology, 18, $101-106$.

Figuerdo, M., Vasquez, G., Brumbach, B., Schneider, S., Sefcek, J., Tal, I., et al. (2006). Consilience and life history theory: from genes to brain in reproductive strategy. Developmental Review, 26, 243-275. doi:10.1016/j.dr.2006.02.002.

Frank, R. (1988). Passions within reason: The strategic role of emotions. New York: W.W. Norton.

Fridlund, A. (1994). Human facial expression: An evolutionary view. San Diego: Academic Press.

Glass, S., \& Newman, J. (2006). Recognition of facial affect in psychopathic offenders. Journal of Abnormal Psychology, 115, 815-820. doi:10.1037/0021-843X.115.4.815.

Glenn, A. L., Kurzban, R., \& Raine, A. (2011). Evolutionary theory and psychopathy. Aggression and Violent Behavior, 16, 371-380. doi: 10.1016/j.avb.2011.03.009.

Griffiths, P. E. (2003). Basic emotions, complex emotions, Machiavellian emotions. Royal Institute of Philosophy Supplement, 52, 39-67. doi: 10.1017/S1358246100007888.

Hager, J. C., \& Ekman, P. (1985). The asymmetry of facial actions is inconsistent with models of hemispheric specialization. Psychophysiology, 22, 307-318.

Hamilton, W. (1964a). The genetical evolution of social behaviour. I. Journal of Theoretical Biology, 7, 1-16. doi:10.1016/00225193(64)90038-4.

Hamilton, W. (1964b). The genetical evolution of social behaviour. II Journal of Theoretical Biology, 7, 17-52. doi:10.1016/00225193(64)90039-6.

Hare, R. D. (1991). Hare Psychopathy Checklist-Revised. Toronto: MHS.

Hare, R. D. (1993). Without conscience: The disturbing world of the psychopaths among us. New York: Pocketbooks.

Hare, R. D. (2001). Psychopaths and their nature: some implications for understanding human predatory violence. In J. Sanmartin \& A. Raine (Eds.), Violence and psychopathy (pp. 5-34). Dordrecht: Kluwer.

Hare, R. D. (2003). The Hare Psychopathy Checklist-Revised (2nd ed.). Toronto: MHS.

Hare, R., \& Neumann, C. (2008). Psychopathy as a clinical and empirical construct. Annual Review of Clinical Psychology, 4, 217-246. doi: 10.1146/annurev.clinpsy.3.022806.091452.

Hinde, R. A. (1985). Expression and negotiation. In G. Zivin (Ed.), The development of expressive behavior (pp. 103-116). New York: Academic Press.

Jonason, P., \& Buss, D. (2012). Avoiding entangling commitments: tactics for implementing a short-term mating strategy. Personality and Individual Differences, 52, 606-610. doi:10.1016/j.paid.2011.12.015.

Jonason, P., \& Webster, G. (2012). A protean approach to social influence: Dark Triad personalities and social influence tactics. Personality and Individual Differences, 52, 521-526. doi:10.1016/j.paid.2011.11.023

Jonason, P. K., Li, N., Webster, G. D., \& Schmitt, D. P. (2009). The dark triad: facilitating a short-termmating strategy in men. European Journal of Personality, 23, 5-18. doi:10.1002/per.698. 
Jonason, P. K., Luevano, V., \& Adams, H. (2012a). How the Dark Triad traits predict relationship choices. Personality and Individual Differences, 53, 180-184. doi:10.1016/j.paid.2012.03.007.

Jonason, P., Slomski, S., \& Partyka, J. (2012b). The Dark Triad at work: how toxic employees get their way. Personality and Individual Differences, 52, 449-453. doi:10.1016/j.paid.2011.11.008.

Jonason, P., Webster, G., Schmitt, D., Li, N., \& Crysel, L. (2012c). The anti-hero in popular culture: Life History Theory and the Dark Triad Personality traits. Review of General Psychology, 16, 192-199. doi: 10.1037/a0027914.

Jones, D. (2014). Predatory personalities as behavioural mimics and parasites: mimicry-deception theory. Perspectives on Psychological Science, 9, 445-451. doi:10.1177/1745691614535936.

Kaufman, A. S., \& Kaufman, N. L. (1990). Kaufman Brief Intelligence Test. Manual. Circle Pines: American Guidance Service.

Kolb, B., \& Taylor, L. (2000). Facial expression, emotion, and hemispheric organization. In R. D. Lane \& L. Nadel (Eds.), Cognitive Neuroscience of Emotion (pp. 63-83). Oxford University Press.

Krupp, D. B., Sewall, L. A., Lalumière, M. L., Sheriff, C., \& Harris, G. T. (2012). Nepotistic patterns of violent psychopathy: evidence for adaptation? Frontiers in Psychology, 3, 1-8. doi:10.3389/fpsyg.2012.00305.

Krupp, D. B., Sewall, L. A., Lalumière, M. L., Sheriff, C., \& Harris, G. T. (2013). Psychopathy, adaptation, and disorder. Frontiers in Psychology, 4(139), 1-5. doi:10.3389/fpsyg.2013.00139.

Levenson, M. R. (1990). Risk taking and personality. Journal of Personality and Social Psychology, 58, 1073-1080.

Levenson, M. R., Kiehl, K. A., \& Fitzpatrick, C. M. (1995). Assessing psychopathic attributes in a noninstitutionalized population. Journal of Personality and Social Psychology, 68, 151-158.

Levenston, G. K., Patrick, C. J., Bradley, M. M., \& Lang, P. J. (2000). The psychopath as observer: emotion and attention in picture processing. Journal of Abnormal Psychology, 109, 373-385.

Lilienfeld, S. O., \& Hess, T. H. (2001). Psychopathic personality traits and somatization: sex differences and the mediating role of negative emotionality. Journal of Psychopathology and Behavioral Assessment, 23, 11-24. doi:10.1023/A:1011035306061.

Lorenz, A. R., \& Newman, J. P. (2002). Deficient response modulation and emotion processing in low-anxious Caucasian psychopathic offenders: Results from a lexical decision task. Emotion, 2, 91-104.

Marsh, A. A., Finger, E. C., Schechter, J. C., Jurkowitz, I. T. N., Reid, M. E., \& Blair, R. J. R. (2011). Adolescents with psychopathic traits report reductions in physiological responses to fear. Journal of Child Psychology and Psychiatry, 52, 834-841. doi:10.1111/j.1469-7610.2010.02353.x.

Matsumoto, D., \& Ekman, P. (1988). Japanese and Caucasian facial expressions of emotion (JACFEE) and neutral faces (JACNeuF). San Francisco: San Francisco State University.

Mealey, L. (1995). The sociobiology of sociopathy: An integrated evolutionary model. Behavioral and Brain Sciences, 18, 523599. doi:10.1017/S0140525X00039595.
Naugle, R. I., Chelune, G. J., \& Tucker, G. D. (1993). The validity of the Kaufman Brief Intelligence Test. Psychological Assessment, 5, 182 186.

Newman, J. P., Patterson, C. M., \& Kosson, D. S. (1987). Response perseveration in psychopaths. Journal of Abnormal Psychology, $96,145-148$

Newman, J. P., Schmitt, W. A., \& Voss, W. D. (1997). The impact of motivationally neutral cues on psychopathic individuals: assessing the generality of the Response Modulation Hypothesis. Journal of Abnormal Psychology, 106, 563-575.

Patrick, C., Bradley, M. M., \& Lang, P. J. (1993). Emotion in the criminal psychopath: Startle reflex modulation. Journal of Abnormal Psychology, 102, 82-92. doi:10.1037/0021-843X.102.1.82.

Patrick, C., Cuthbert, B., \& Lang, P. (1994). Emotion in the criminal psychopath: Fear image processing. Journal of Abnormal Psychology, 103, 523-534. doi:10.1037/0021-843X.103.3.523.

Paulhus, D. L., \& Williams, K. M. (2002). The dark triad of personality: Narcissism, Machiavellianism, and psychopathy. Journal of Research in Personality, 36, 556-563. doi:10.1016/S0092-6566(02) 00505-6.

Premack, D., \& Woodruff, G. (1978). Does the chimpanzee have a theory of mind? The Behavioral and Brain Sciences, 4, 515-526.

Richell, R. A., Mitchell, D. G. V., Newman, C., Leonard, A., BaronCohen, S., et al. (2003). Theory of mind and psychopathy: can psychopathic individuals read the 'language of the eyes'? Neuropsychologia, 41, 523-526.

Richell, R. A., Mitchell, D. G. V., Peschardt, K. S., Winston, J. S., Leonard, A., et al. (2005). Trust and distrust: the perception of trustworthiness of faces in psychopathic and non- psychopathic offenders. Personality and Individual Differences, 38, 1735-1744.

Seto, M., Khattar, N. A., Lalumiere, M., \& Quinsey, V. L. (1997). Deception and sexual strategy in psychopathy. Personality and Individual Differences, 22, 301-307. doi: 10.1016/S0191-8869(96)00212-7.

Trivers, R. L. (1971). The evolution of reciprocal altruism. The Quarterly Review of Biology, 46, 35-57.

Veit, R., Konicar, L., Klinzing, J., Barth, B., Yilmaz, O., \& Birbaumer, N. (2013). Deficient fear conditioning in psychopathy as a function of interpersonal and affective disturbances. Frontiers in Human Neuroscience, 7, 1-12. doi:10.3389/fnhum.2013.00706.

Visser, B., DeBow, V., Pozzebon, J., Boegart, A., \& Book, A. (2015). Psychopathic sexuality: The thin line between fantasy and reality. Journal of Personality. doi:10.1111/jopy.12110.

Wilson, K., Juodis, M., \& Porter, S. (2011). Fear and loathing in psychopaths: a meta-analytic investigation of the facial affect recognition deficit. Criminal Justice and Behavior, 38, 659668. doi:10.1177/0093854811404120.

Woodworth, M., \& Waschbusch, D. (2008). Emotional processing in children with callous/unemotional traits. Child: Care, Health and Development, 34, 234-244. doi:10.1111/j.1365-2214.2007.0079. 